\title{
Appraisal of Surface Modified AISI 316 L Stainless Steels by Plasma and Solid Nitriding Techniques
}

\author{
R. Guardian, I. Rosales-Cadena*, J. L. Valle-Mata, J. Pereyra-Hernández, 0. Ocampo \\ Center of Research in Engineering and Applied Science, CIICAp - UAEM., Cuernavaca, Mexico \\ Email: ${ }^{\star}$ faye12@uaem.mx
}

How to cite this paper: Guardian, R. Rosales-Cadena, I., Valle-Mata, J.L., Pereyra-Hernández, J. and Ocampo, O. (2020) Appraisal of Surface Modified AISI 316 L Stainless Steels by Plasma and Solid Nitriding Techniques. Materials Sciences and Applications, 11, 462-473. https://doi.org/10.4236/msa.2020.117032

Received: June 2, 2020

Accepted: July 14, 2020

Published: July 17, 2020

Copyright ( 2020 by author(s) and Scientific Research Publishing Inc. This work is licensed under the Creative Commons Attribution International License (CC BY 4.0).

http://creativecommons.org/licenses/by/4.0/

\section{(c) (i) Open Access}

\begin{abstract}
AISI $316 \mathrm{~L}$ stainless steels type was surface modified by ion and solid nitriding treatment. It was demonstrated that a surface activation pretreatment in samples based in acid mixture accompanied with $\mathrm{NH}_{4} \mathrm{NO}_{3}$ solution inside the container, can produce an efficient nitrogen diffusion process. As compared with ion nitriding treatment $\left(20 \% \mathrm{~N}_{2}-80 \% \mathrm{H}_{2}\right)$, the samples were treated with solid nitriding technique, using $\mathrm{Fe}_{4} \mathrm{KCN}$ based compound at the same time and temperature $\left(6 \mathrm{~h}\right.$ and $500^{\circ} \mathrm{C}$ respectively). Superficial layers with a depth of $45 \mu \mathrm{m}$ average were obtained with six hours treatment. Hardness surface values of two surface treatments present an increased value of approximately three times with respect to the matrix sample. Wear evaluation indicated low regimes of weight losses for both treatments. Oxidative-adhesive result is to be the predominant operating wear mechanism. Positive results were obtained in solid nitriding technique as compared with the expensive ion nitriding technique.
\end{abstract}

\section{Keywords}

Surface Modification, Hardness, Mechanical Properties, Wear

\section{Introduction}

Strengthened tools and components are necessaries for industrial applications in several processes, where exists a relative contact between surfaces. Surface engineering involves a series of process to obtain hardened surfaces that improve the service life of industrial machinery components. It is well known that among the different thermal surface treatments, nitriding is one of the most important, because it offers many advantages such as uniform surface stability, no dimension- 
al affectation and well controlled depth of layer [1] [2] [3] [4]. It has been reported that the main cause for the hardness increment in nitrided steels is produced mainly by the nitrides precipitated during the process [1]. This is because nitriding reaction not only occurs on the surface sample, but also simultaneously in the subsurface, due to the continuous diffusion of nitrogen atoms. Surface modification based in nitriding processes, possesses significant advantages versus another superficial hardening techniques [2] [3] [4]. Surface modification about stainless steels has been extensively developed, providing important information about the nitrided layer for different applications [5] [6] [7]. The purpose of the present work is to study the mechanical properties of the modified surfaces by ion and solid nitriding of AISI 316L type stainless steel. Also the results explain the effect of a surface activation by chemical pretreatment, together with the application of a nitrogen based reactant, in order to improve the nitrogen atmosphere and therefore an enhanced nitrogen diffusion (in solid nitriding). Results were focused in show that solid nitriding can be an accessible and no expensive surface treatment to obtain hardened layers in many components, used carefully (because is not a green process) when ion nitriding treatment is not accessible.

\section{Experimental Procedure}

\subsection{Sample Preparation}

AISI 316L type stainless steel was used to perform the present investigation (see Table 1 for chemical compositions). Several specimens of this steel were obtained by cutting coupons with dimensions of $1 \times 1 \times 1 \mathrm{~cm}$, grinded and surface polished with alumina up to $1.0 \mu \mathrm{m}$.

\subsection{Surface Modification Process}

Before nitriding treatments, samples were superficially pretreated with a based $\mathrm{HNO}_{3}, \mathrm{HCl}$ and $\mathrm{HF}$ solution for $2 \mathrm{~h}$. For ion nitriding treatment, samples were thermo-chemical treated during $6 \mathrm{~h}$, at $500^{\circ} \mathrm{C} \pm 10^{\circ} \mathrm{C}$ (the selected temperature was considered for no corrosion applications), $480 \pm 15 \mathrm{~V}$, using a gas mixture of $20 \% \mathrm{~N}_{2}-80 \% \mathrm{H}_{2}$ with an internal pressure of 20 Torr. For the case of solid nitriding, samples were surrounded (20 mm thickness) with a Potassium Ferrocyanide $\left(\mathrm{Fe}_{4} \mathrm{KCN}\right)$ based compound inside of a hermetic stainless steel container internally coated with ammonia nitrate solution $\left(\mathrm{NH}_{4} \mathrm{NO}_{3}\right)$ to enhance the nitrogen diffusion. After that, the container was placed inside of a furnace chamber and heated at $500^{\circ} \mathrm{C} \pm 5^{\circ} \mathrm{C}$ during $6 \mathrm{~h}$.

Table 1. Chemical composition of the stainless steel AISI 316L used in the experiments.

\begin{tabular}{lccccccc}
\hline AISI 316L & $\mathrm{C}$ & $\mathrm{Si}$ & $\mathrm{Mn}$ & $\mathrm{Cr}$ & $\mathrm{Ni}$ & $\mathrm{Mo}$ & $\mathrm{Fe}$ \\
\hline & 1.0 & 2.0 & 18.0 & 11.50 & 2.30 & Bal. \\
\hline
\end{tabular}




\subsection{Surface Characterization}

Chemical analyses and surfaces observations were performed in a LEO-1450VP scanning electron microscope. X-ray diffraction (XRD) analyses were carried out in a Siemens D5000 diffractometer with copper radiation $\mathrm{CuKa}(\lambda=1.5405 \mathrm{~A})$. Vickers microhardness profiles were performed trough the polished cross-section samples, using a $0.2 \mathrm{~kg}$ load and a holding time of $15 \mathrm{~s}$, using a Leco $300 \mathrm{MT}$ micro-hardness tester. A conventional pin-on-disk wear system was employed to evaluate the wear behavior of the pin-samples with dimensions of $6 \mathrm{~mm}$ diameter by $8 \mathrm{~mm}$ length, under a load of $1 \mathrm{MPa}$, with a constant disk speed of 100 rpm and zero lubrication. AISI-4140 steel (oil quenched) was used as counterpart disk with a hardness of $51 \pm 3$ HRC. Worn surfaces were observed and analyzed in the SEM.

\section{Results and Discussion}

\subsection{SEM Characterization}

Figure 1(a) shows the cross section of the ion nitriding treatment sample after polishing process. It is observed that sample presents a width of layer of approximately $45 \mu \mathrm{m}$ average, distributed homogeneously along the surface sample; it is notorious that a interlayer is developed between the sample matrix and the nitrided layer where the layer width is of approximately $4 \mu \mathrm{m}$ composed by expanded austenite (marked by arrows) which has been created due to the saturation of nitrogen in the FCC austenite [8]. Moreover, it can be observed in Figure 1(b) the cross section of sample with solid nitriding treatment, which presents a layer with an average width of $50 \mu \mathrm{m}$. In other steels types, the morphology of nitrided layers with several nitriding processes (including solid nitriding) have been studied [9] [10] reporting a similar behavior. Analyzing both treatments it is observed that only sample ion nitrided, developed the expanded austenite interlayer.

\subsection{Nitrogen Diffusion}

Figure 2 shows the nitrogen diffusion profiles obtained after the nitriding processes. It can be observed that, the nitrogen diffusion (measured from the surface to the inner sample) for ion nitriding process, reaches a depth value of approximately $60 \mu \mathrm{m}$ with an starting surface concentration of $23 \mathrm{wt} \%$, while for solid nitriding the depth values is of $40 \mu \mathrm{m}$ approximately with a surface concentration detected of $6 \mathrm{wt} \%$. These results show a nitrogen diffusion of almost 50 percent more for the ion nitriding sample in comparison with the solid nitrided samples. Although, it is noticeable that sample with solid nitriding treatment at this nitrogen concentration, presents an improved diffusion behavior, it can be attributed to the nitrogen rich atmosphere generated inside the container which come from the reactant and the internal ammonia nitrate coating, generating a strong influence in the diffusion process with the consecutive formation not only of nitrides and carbides but also carbonitrides with the elements alloy 


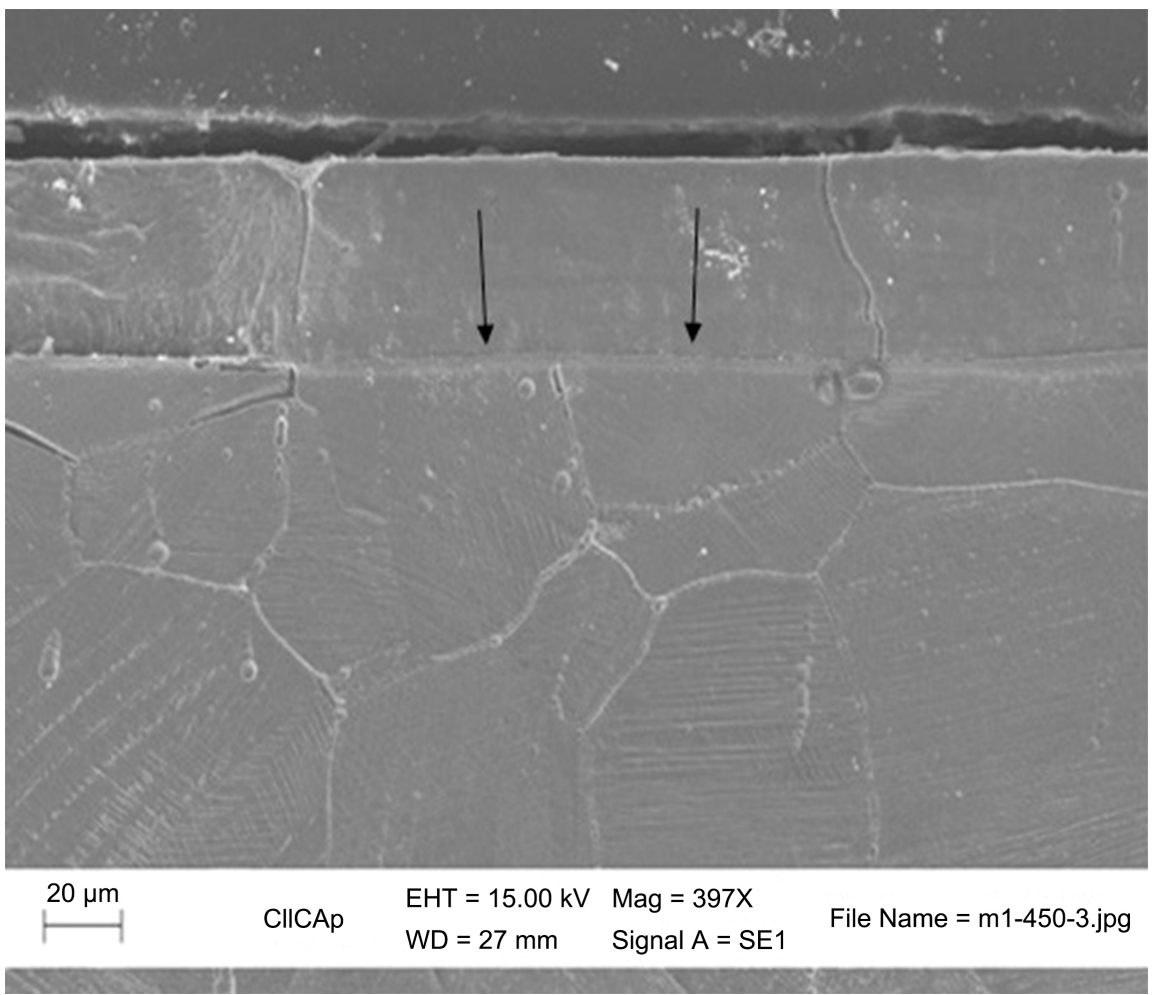

(a)

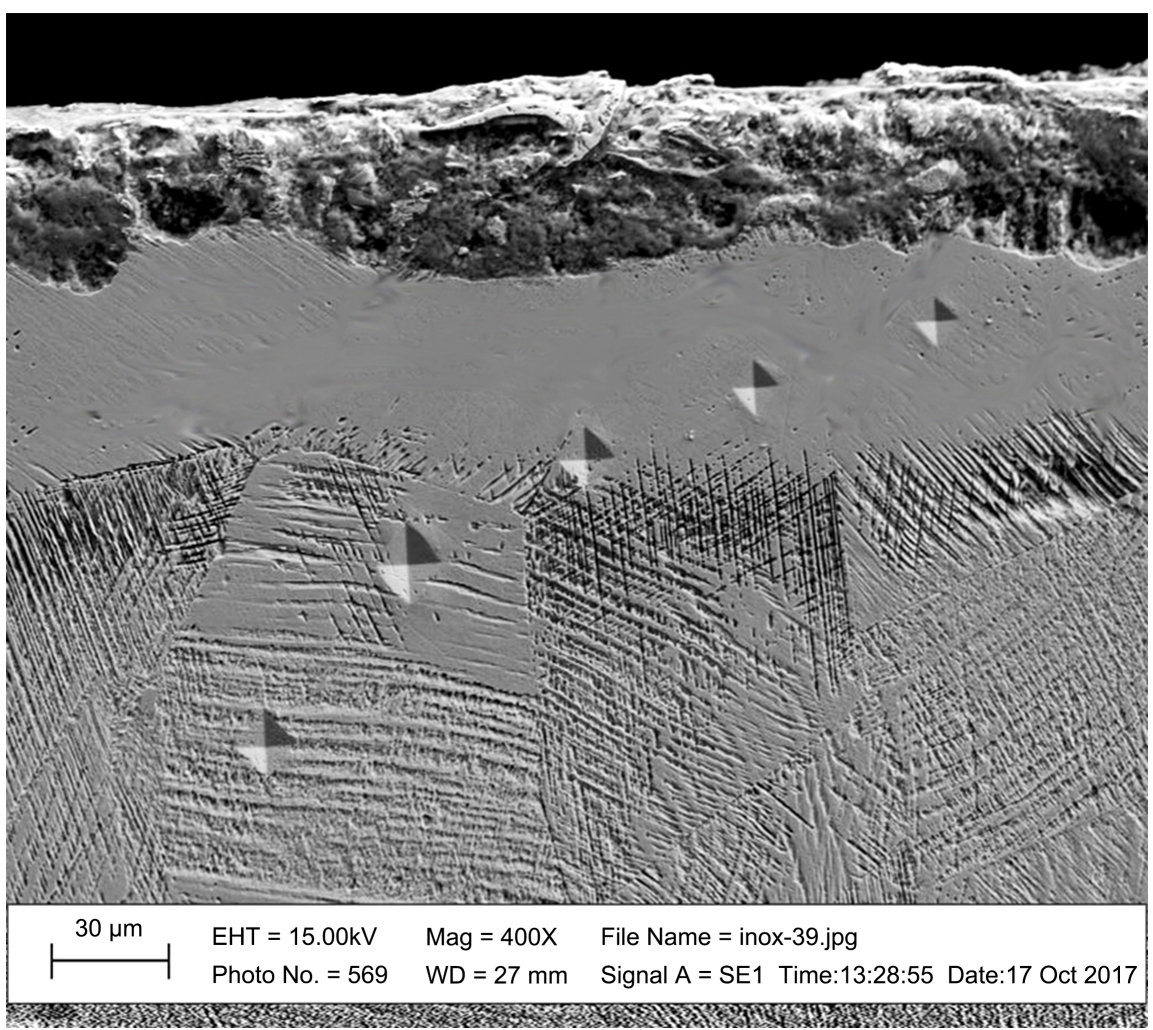

(b)

Figure 1. (a) Cross section of the sample with ion nitriding treatment showing the nitriding layer and the expanded austenite layer; (b) Cross section of the solid nitrided sample after polishing process. 


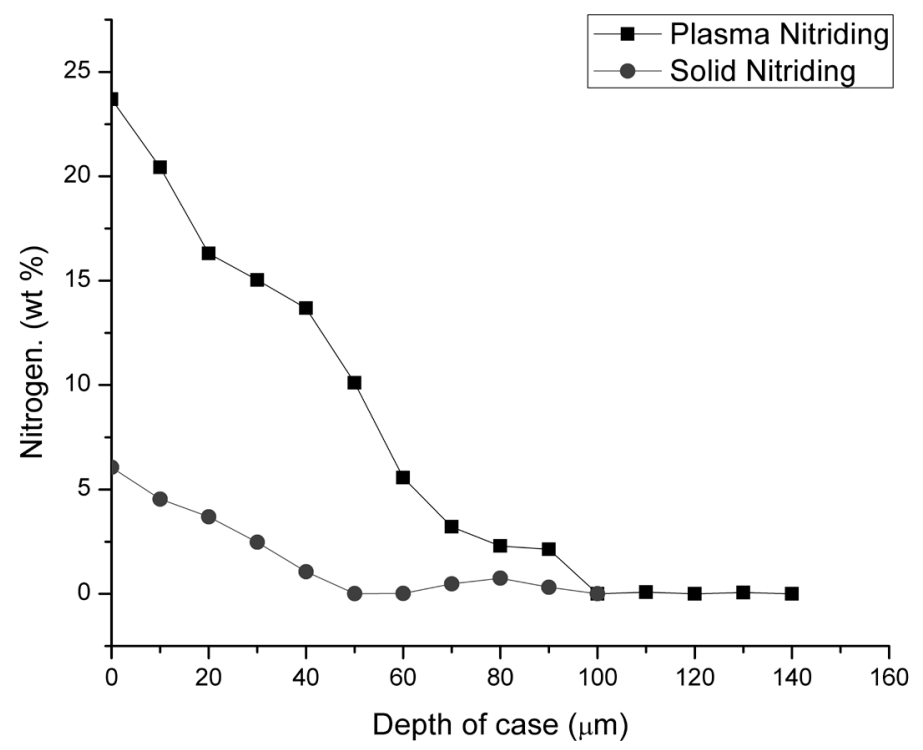

Figure 2. Plots of the nitrogen diffusion profiles obtained after the nitriding and solid nitriding processes.

present in the steel [11]. Nitrogen source was obtained from the reactant potassium ferrocyanide $\left(\mathrm{Fe}_{4} \mathrm{KCN}\right)$ plus Ammonium nitrate which under heating atmosphere decomposes to produce nitrous oxide and water in agreement with the follow reaction:

$$
\mathrm{NH}_{4} \mathrm{NO}_{3} \rightarrow \mathrm{N}_{2} \mathrm{O}+2 \mathrm{H}_{2} \mathrm{O}
$$

Therefore, using the oxygen from the evaporated water, the following reactions are proposed in order to obtain the necessary nitrogen in the diffusion process:

$$
\begin{gathered}
\mathrm{O}+\mathrm{N}_{2} \mathrm{O} \rightarrow 2 \mathrm{NO} \\
\mathrm{N}_{2} \mathrm{O}+\mathrm{NO} \rightarrow \mathrm{N}_{2}+\mathrm{NO}_{2} \\
\mathrm{~N}_{2}+\mathrm{O} \rightarrow \mathrm{N}+\mathrm{NO}
\end{gathered}
$$

Consequently, because nitrogen and carbon possesses an atomic radii of 0.54 and $0.65 \AA$ respectively, then, nitrogen presents higher possibility to diffuse inwards to the austenitic structure, precipitating nitrides compounds, then carbon also diffuses producing the carbonitride formation. Several authors have reported deviations in thickness layer for this effect in Cr alloyed steels [5] [6].

\subsection{XRD Analysis}

In Figure 3 are shown the XRD patterns for the stainless steel samples in three different conditions, namely sample without treatment, sample plasma nitrided, and sample solid nitrided. For plasma nitriding treatment, due to $\mathrm{Cr}_{2} \mathrm{~N}$ is thermodynamically more stable than $\mathrm{CrN}$, the possibility to produce $\mathrm{Cr}_{2} \mathrm{~N}$ increases, and therefore it become the main phase in the nitrided layer in combination with $\mathrm{Fe}_{4} \mathrm{~N}$ and $\mathrm{Fe}_{2} \mathrm{~N}$ as is showed in the XRD spectrum. In the case of solid nitriding, the nitrogen source, to precipitate chromium nitride, comes mainly 


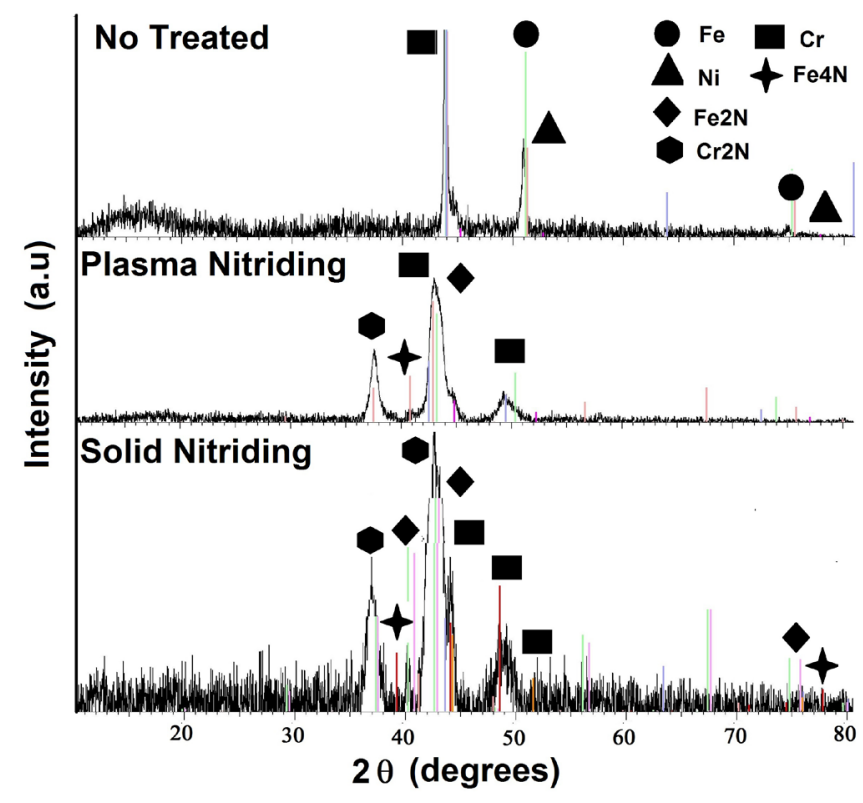

Figure 3. X-ray diffraction patterns for the stainless steel samples with three different conditions (plasma nitriding, solid nitriding and sample without treatment).

from the decomposition of the supplied nitrogen source, and inside the internal coating in the container, for consequence, exists enough $\mathrm{C}$ and $\mathrm{N}$ atoms to create different precipitates, so that, substitutional nitrogen and carbon atoms (which are affected by the temperature treatment) possess sufficient mobility to allow nucleation and growth of precipitates such as carbides, nitrides and also carbonitrides. Therefore, the kinetics reaction for nitrogen to binds chromium and carbon for produce carbonitrides can be via the following reactions:

$$
\begin{gathered}
\mathrm{Cr}+\mathrm{CN} \rightarrow \mathrm{Cr}(\mathrm{N}, \mathrm{C}) \\
2 \mathrm{Cr}+\mathrm{CN} \rightarrow \mathrm{Cr}_{2}(\mathrm{~N}, \mathrm{C})
\end{gathered}
$$

Because carbonitrides possesses hexagonal structure and steel structure is fcc type, then is highly probably to obtain a semi-coherent interphase between the new layer (formed with nitrides plus carbonitrides) with the matrix, due to the fact that a strong link interaction can be promoted by the reached temperature.

\subsection{Mechanical Properties}

\subsubsection{Microhardness Evaluation}

Microhardness profiles obtained from the cross section of nitrided samples are shown in Figure 4, where it can be observed that the sample with solid nitriding, hardening in the zone close to the surface treatment, presents a hardness value of $860 \mathrm{~kg} / \mathrm{mm}^{2}$. This value represents $100 \mathrm{~kg} / \mathrm{mm}^{2}$ less than sample with plasma nitriding treatment $\left(950 \mathrm{~kg} / \mathrm{mm}^{2}\right)$; therefore, surface hardness diminishing is attributed mainly to the surface oxidation carried out during the treatment, due to the contact of the reactive with the surface sample, producing a porous surface [12]. In the case of the plasma nitride sample, between 15 and $20 \mu \mathrm{m}$ below the 


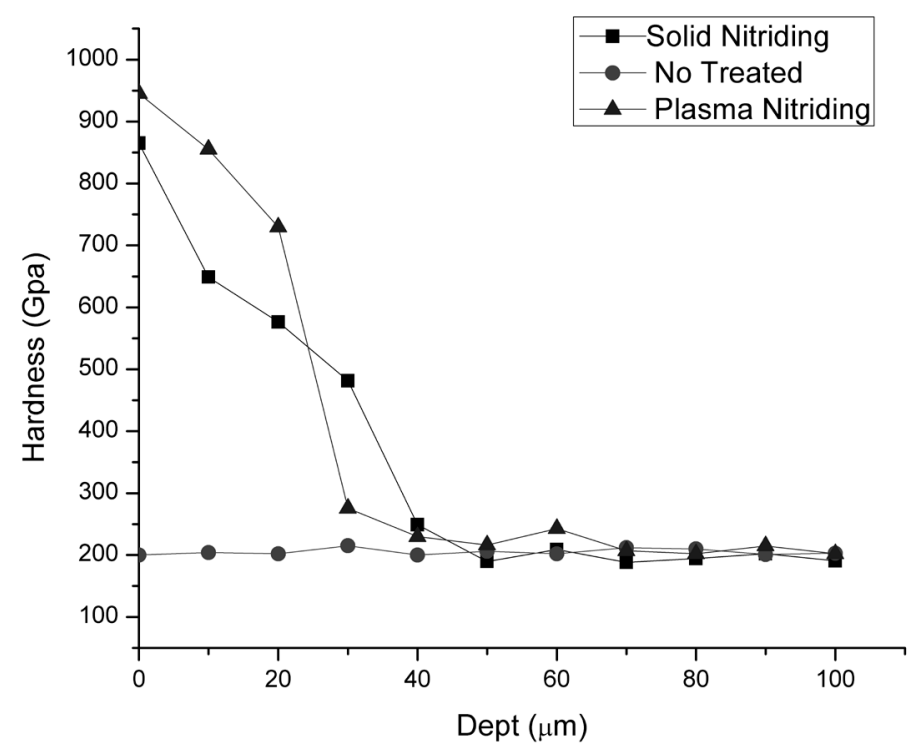

Figure 4. Microhardness profiles measured from the cross section of the studied samples taken from the top trough the matrix sample.

surface, the hardness value remains higher as compared with the solid nitriding sample, however it is interesting to note that between 20 to $40 \mu \mathrm{m}$ below the surface, the hardness value in solid nitride sample is higher than the values of the plasma nitriding sample in approximately $200 \mathrm{~kg} / \mathrm{mm}^{2}$, such increment can be explained in terms of lattice distortion, when carbon and nitrogen atoms are introduced in the crystal structure, this phenomenon has been observed by $\mathrm{X}$. Xu [7], whom postulated that lattice distortion after plasma nitriding is related to the different arrangement of the nitrogen atoms in the fcc lattice at different nitrogen contents. For a depth value higher than $20 \mu \mathrm{m}$, the hardness value of the sample with plasma nitriding treatment decreases abruptly, reaching a value similar to the sample without thermal treatment. Other authors [13] studied the surface hardening behavior of tool steels by using ion and solid nitriding treatment methods, reporting similar behavior in hardness for solid nitriding when is compared with plasma nitriding.

In Figure 5 and Figure 1(b) are observed the indentations carried out along the nitriding layer for plasma and solid nitriding, respectively. The images show the indentation pattern and the transition of the size indent (variation) across the hardened layer, from the surface sample through the nitride layer, showing the effectiveness of both treatments to produce a hardened layer. Because austenitic stainless steels cannot be strengthened by a conventional heat treatment process, due to its crystal structure, then the thermochemical process is one of the best ways to get better hardness in the steel.

\subsubsection{Wear Behaviour}

Figure 6 presents the curves of the weight losses against sliding distance for the samples with plasma and solid nitriding treatment, where it is important to note that the initial wear rate, for the sample with plasma nitriding, presents very low 


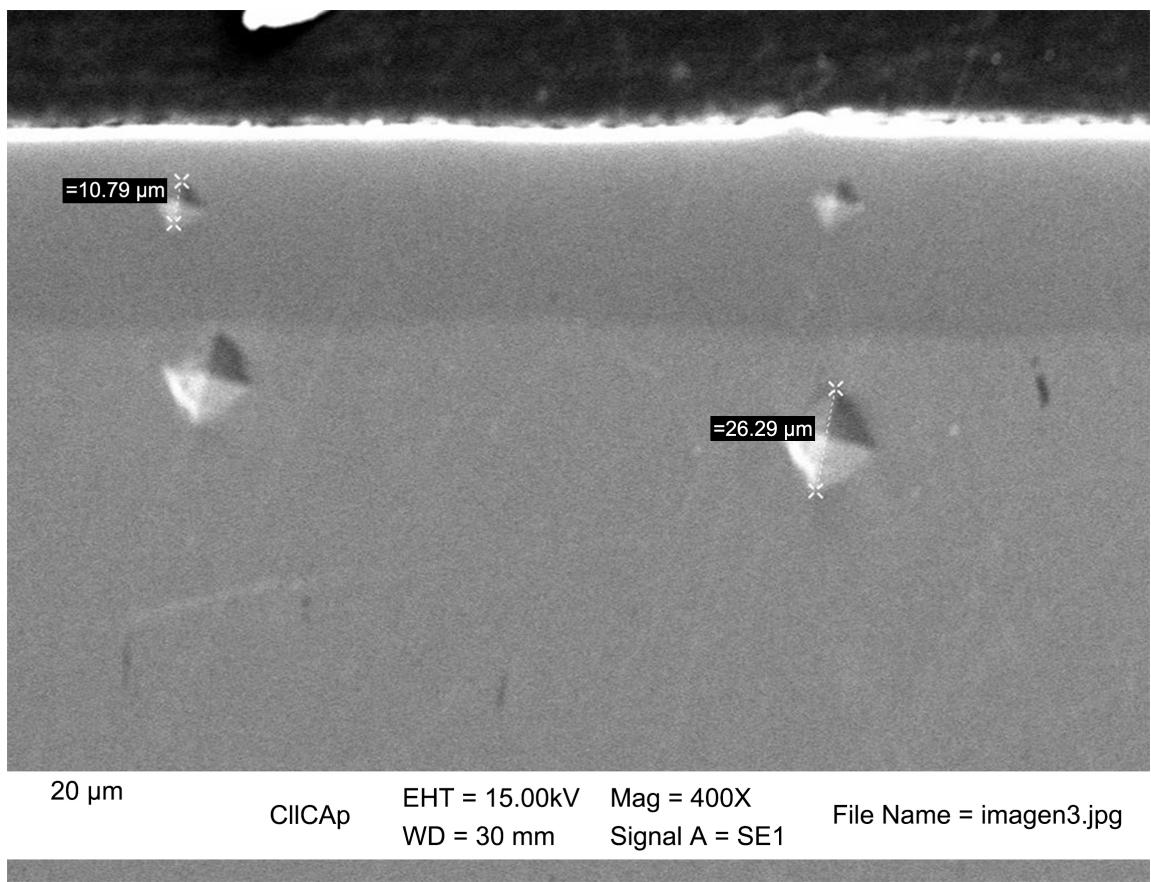

Figure 5. Image of the indentations carried out along the nitriding layer for plasma nitriding (indentations in sample solid nitride are presented in Figure 1(b)).

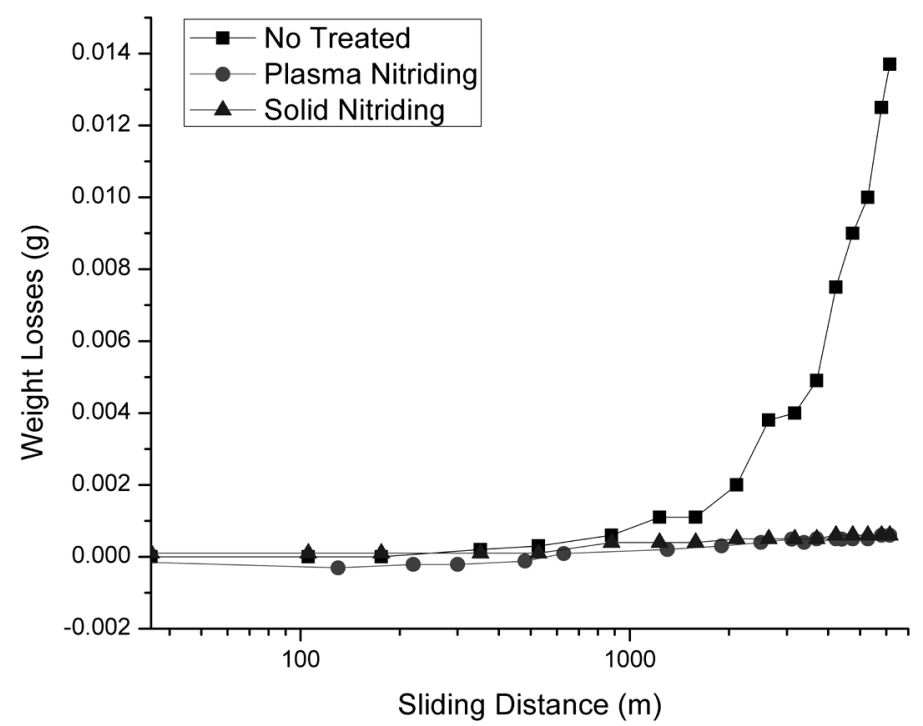

Figure 6. Plot of the weight losses vs. sliding distance for the samples with plasma and solid nitriding.

regimes, accompanied also with negatives values (gain weight) above to one thousand meters, indicating an oxide formation process and therefore an oxidative-adhesive mechanism [14]. However, this wear plot, describes a similar plateau in comparison with the plot of solid nitriding treatment sample, without a considerable variation in weight loss during the wear test, indicating a very low friction coefficient (see Table 2), which permits an easy sliding movement, between the surface sample and the counterpart; besides, the plots have shown that 
both samples present similar behaviour in weight loss under this specific applied load.

The SEM micrographs of wear track in ion and solid nitriding samples are shown in Figure 7 and Figure 8 respectively, where it can be observed an oxidized surface with few scratches along the sliding surface in the worn surface of ion nitride sample. These surface oxides are produced due to the elevated temperatures generated by the friction between pin and counterpart, therefore the predominant wear mechanism for this sample is generally of oxidative-adhesive type. Thus, in some areas of the worn surface, the resultant layers are fractured because of the accumulated stresses, producing a layer depletion, which plays a determinant role as an abrasive particle [10] and due to the intrinsic nature of the nitrided layer. Therefore, if these particles tend to decrease the formation of a protective oxide layer, then it is suggested that the contact between the surfaces

Table 2. Wear results obtained from the evaluation based on the wear plots and surface hardness values in sample in the three different conditions.

\begin{tabular}{cccc}
\hline Sample & $\begin{array}{c}\text { Wear Factor } \\
{[\mathrm{g} / \mathrm{m}]}\end{array}$ & Friction coefficient & $\begin{array}{c}\text { Surface Hardness } \\
{\left[\mathrm{kg} / \mathrm{mm}^{2}\right]}\end{array}$ \\
\hline Plasma Nitriding & $1.86 \times 10^{-7}$ & 0.234 & $948 \pm 12$ \\
Solid Nitriding & $0.94 \times 10^{-7}$ & 0.237 & $875 \pm 8$ \\
No treated & $2.095 \times 10^{-6}$ & 0.354 & $225 \pm 5$ \\
\hline
\end{tabular}

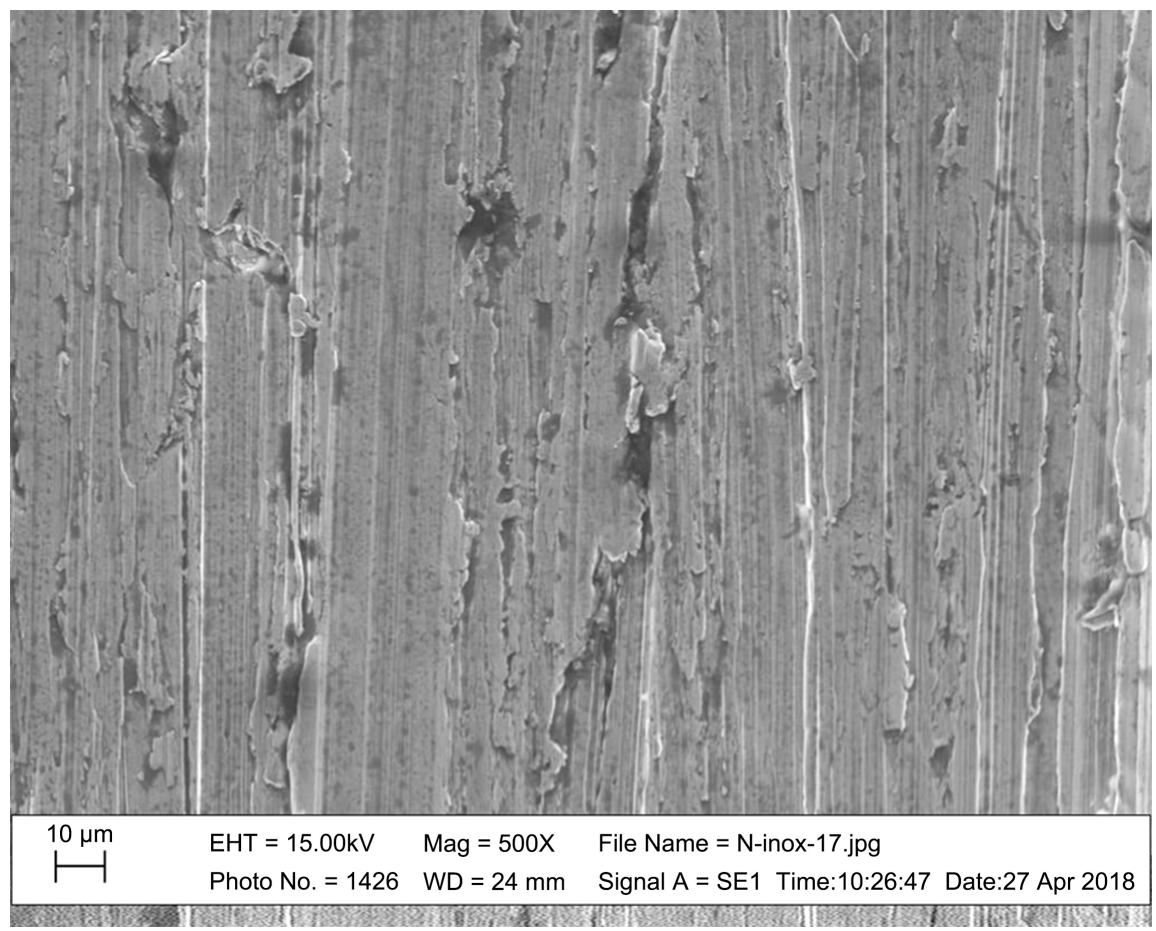

Figure 7. SEM micrograph of wear track in sample ion nitriding in which small particles are detected inner of the observed grooves. 


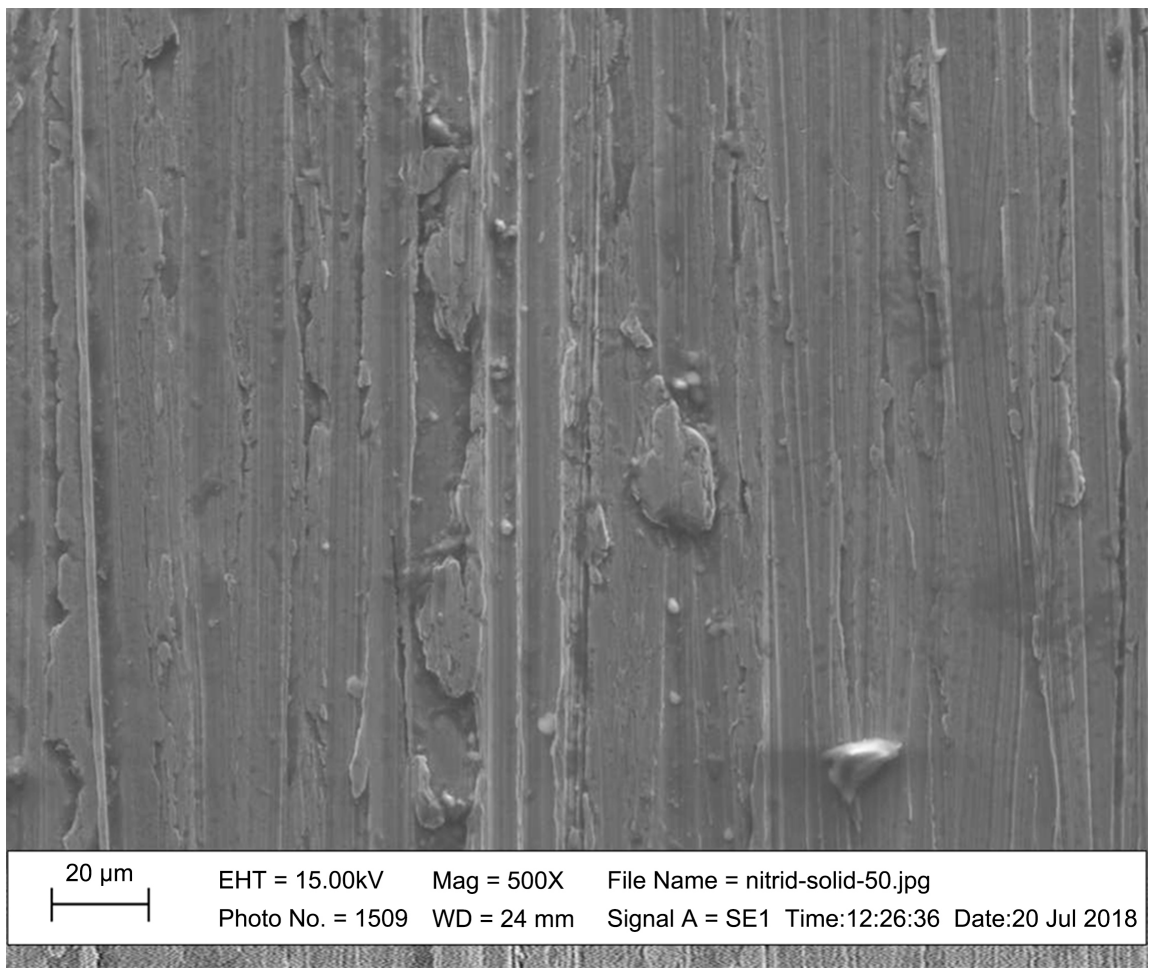

Figure 8. SEM micrographs of the worn surface of sample solid nitride with several oxidized regions.

generates a moderate friction rate, producing in these alloys an operating wear mechanism of abrasive type. In Table 2 is presented the wear factor and the friction coefficient, calculated from the plots after the wear tests, where it is clear the improved behavior of the nitrided samples in comparison with the untreated samples. After this careful evaluation, it is noticeable that both nitriding samples present almost the same behavior, which is one favorable result of the present investigation.

Figure 9 presents the chemical analysis of the surface sample with solid nitriding treatment generated after wear test; as it was expected, chromium, nickel, iron and oxygen were detected with higher intensity (plus other alloying elements in minor intensity), where it is corroborated that effectively this elements become part of the oxides generated during the wear process, mainly from the worn surface sample. Although, this result do not exclude the possibility that nitrogen oxides can be developed simultaneously [12].

\section{Conclusion}

AISI 316L type stainless steel with two different nitriding treatments namely plasma and solid nitriding was analyzed. A remarkable morphology difference was observed in the sample with plasma nitriding where a clean surface was obtained, while in sample with solid nitriding the surface sample presents a contaminated layer and additional rectification process (a disadvantage) needs to be applied. Similar thickness values of the nitriding layers obtained in both 


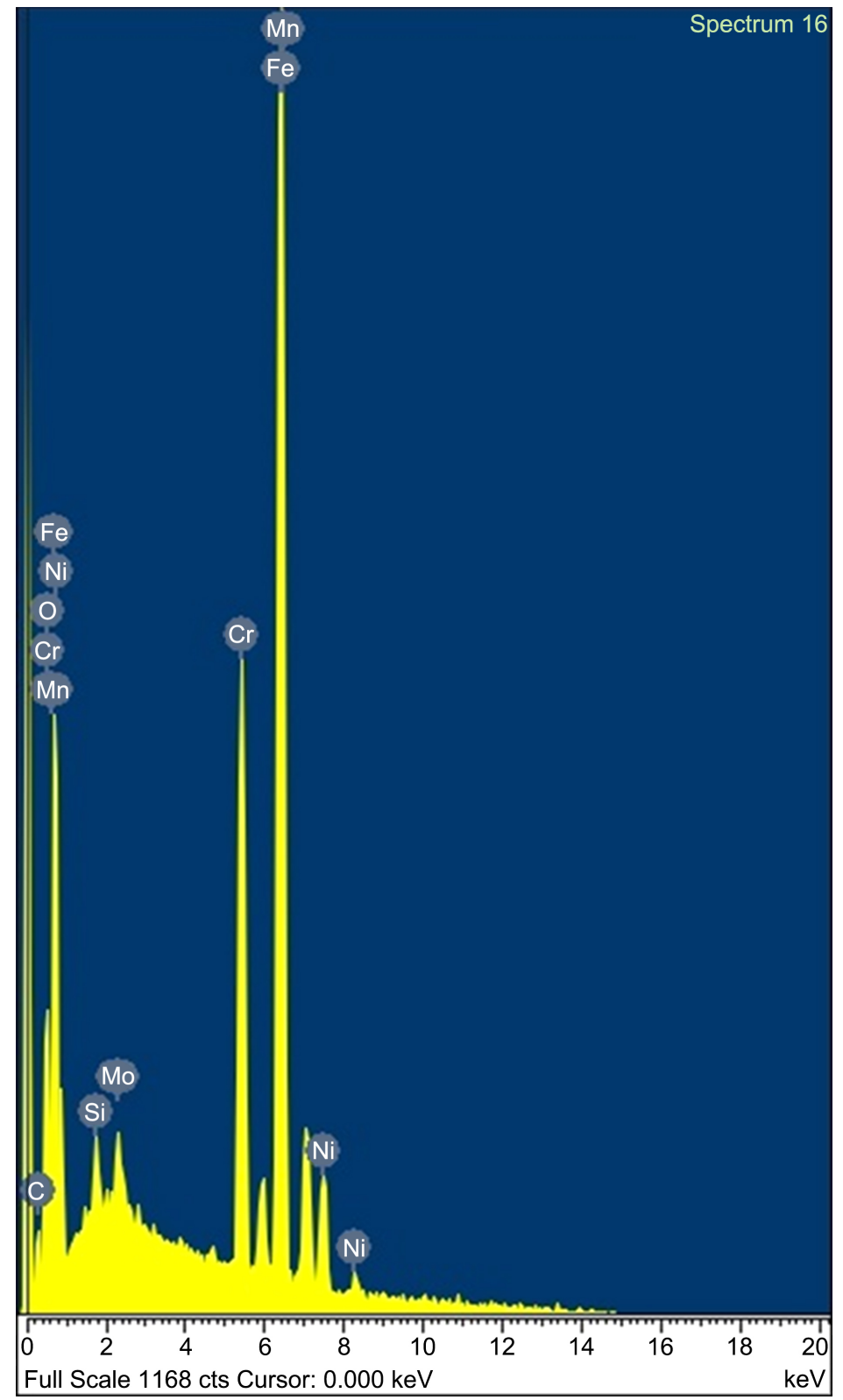

Figure 9. Chemical analysis of the surface sample with solid nitriding treatment after wear test, showing the strong oxygen presence.

treatments. Improved wear behavior was observed in sample with solid nitriding treatment, in which the oxidative-adhesive mechanism occurs. Based on the former results, it is concluded that the main advantage of solid nitriding treatment can be the production costs for some industrial applications with acceptable results.

\section{Acknowledgements}

The authors are grateful with PRODEP for financial support under grant UAEM-PTC-074 and CONACyT-S53120-Y. Technical support from J. Macedonio, A. Aguilar is recognized. 


\section{Conflicts of Interest}

The authors declare no conflicts of interest regarding the publication of this paper.

\section{References}

[1] Munz, W.D., Hofmann, D. and Harting, K. (1982) A High Rate Sputtering Process for the Formation of Hard-Reducing TiN Coatings of Tools. Thin Solid Films, 96, 79-86.

[2] Christiansen, T. and Somers, M.A.J. (2006) Characterization of Low Temperature Surface Hardened Stainless Steel. Struers, Journal of Metallography, 9, 2-17. http://orbit.dtu.dk/en/publications/characterisation-of-low-temperature-surface-ha $\underline{\text { rdened-stainless-steel(1c6daebb-3a17-4540-9ec1-5f095f92e104).html }}$

[3] Devaraju, A., Elayaperumal, A., Alphonsa, J., Kailas, S.V. and Venugopal, S. (2012) Microstructure and Dry Sliding Wear Resistance Evaluation of Plasma Nitride Austenitic Stainless Steel Type AISI 316LN against Different Sliders. Surface and Coatings Technology, 207, 406-412.

[4] Gunzel, R., Betzl, M., Alphonsa, I., Granguly, B., John, P.I. and Mukerjee, S. (1999) Plasma Source Ion Implantation Compared with Glow-Discharge Plasma Nitriding of Stainless Steel. Surface and Coatings Technology, 112, 307-309.

[5] Ashrafizadeh, F. (2003) Influence of Plasma and Gas Nitriding on Fatigue Resistance of Plain Carbon (Ck45) Steel. Surface and Coatings Technology, 173-174, 1196-1200.

[6] Allen, C., Li, C.X., Bell, T. and Sun, Y. (2003) The Effect of Fretting on the Fatigue Behaviour of Plasma Nitrided Stainless Steels. Wear, 254, 1106-1112.

[7] Xu, X., Yu, Z., Wang, L., Qiang, J. and Hei, Z. (2003) Phase Depth Distribution Characteristics of the Plasma Nitrided Layer on AISI 304 Stainless Steel. Surface and Coatings Technology, 162, 242-247.

[8] Liang, W. (2003) Surface Modification of AISI 304 Austenitic Stainless Steel by Plasma Nitriding. Applied Surface Science, 211, 308-314.

[9] Baranowska, J. (2004) Characteristic of the Nitrided Layers on the Stainless Steel at Low Temperature. Surface and Coatings Technology, 180-181, 145-149.

[10] Wei, R., Vajo, J.J., Matossian, J.N., Wilbur, P.J., Davis, J.A., Williamson, D.L. and Collins, G.A. (1996) A Comparative Study of Beam Ion Implantation, Plasma Ion Implantation and Nitriding of AISI 304 Stainless Steel. Surface and Coatings Technology, 83, 235-242.

[11] Gorbachev, I., Popov, V.V. and Pasynkov, A.Yu. (2012) Thermodynamic Simulation of the Formation of Carbonitrides in Steels with $\mathrm{Nb}$ and Ti. The Physics of Metals and Metallography, 113-117, 687-695.

[12] Binder, C., Bendo, T., Hammes, G., Klein, A.N. and de Mello, J.D.B. (2015) Effect of Nature of Nitrided Phases on Sliding Wear of Plasma Nitrided Sintered Iron. Wear, 332-333, 995-1005.

[13] dos Santos de Almeida, E.A., Giubilei Milan, J.C. and Edil da Costa, C. (2015) Acquired Properties Comparison of Solid Nitriding, Gas Nitriding and Plasma Nitriding in Tool Steels. Materials Research, 18-1, 27-35.

[14] Wang, L., Ji, S. and Sun, J. (2006) Effect of Nitriding Time on the Nitrided Layer of AISI 304 Austenitic Stainless Steel. Surface and Coatings Technology, 200, 5067-5070. 